This is the author's final, peer-reviewed manuscript as accepted for publication. The publisher-formatted version may be available through the publisher's web site or your institution's library.

\title{
Democratic community initiatives: the case of overscheduled children
}

Jared R. Anderson and William J. Doherty

\section{How to cite this manuscript}

If you make reference to this version of the manuscript, use the following information:

Anderson, J. R., \& Doherty, W. J. (2005). Democratic community initiatives: The case of overscheduled children. Retrieved from http://krex.ksu.edu

\section{Published Version Information}

Citation: Anderson, J. R., \& Doherty, W. J. (2005). Democratic community initiatives:

The case of overscheduled children. Family Relations, 54(5), 654-665.

Copyright: Copyright 2005 by the National Council on Family Relations

Digital Object Identifier (DOI): doi:10.1111/j.1741-3729.2005.00349.x

Publisher's Link:

http://onlinelibrary.wiley.com/doi/10.1111/j.1741-3729.2005.00349.x/full

This item was retrieved from the K-State Research Exchange (K-REx), the institutional repository of Kansas State University. K-REx is available at http://krex.ksu.edu 


\section{Running Head: DEMOCRATIC COMMUNITY INITIATIVES}

Democratic Community Initiatives: The Case of Overscheduled Children

Jared R. Anderson and William J. Doherty

University of Minnesota

Jared R. Anderson, M.S., Doctoral Student, Department of Family Social Science, University of Minnesota; William J. Doherty, Ph.D., Professor, Department of Family Social Science, University of Minnesota.

Address correspondence to: Jared R. Anderson, Department of Family Social Science, University of Minnesota, 290 McNeal Hall, St. Paul, MN 55108; e-mail: ande3525@umn.edu 


\begin{abstract}
We describe a democratic citizen model of community organizing for mobilizing and partnering with families, using the overscheduling of children as a case example. We provide an overview of the growing body of research on this aspect of family time, describe the difference between a citizen model and program models for working with families, give two examples of community initiatives initiated by family professionals, describe next steps for evaluating this community organizing model, and offer implications for family professionals.
\end{abstract}

Key Words: family time, community initiatives, community, evaluation, overscheduled children 
Community initiatives and community organizing have their roots in the late nineteenth century settlement house movement (Trolander, 1987) and the early twentieth century community organizing strategies used to improve the physical environments of neighborhoods and the living conditions of its citizens (Alinsky, 1969). The past two decades has seen a dramatic rise in community initiatives targeting everything from affordable housing (Knight Foundation, 2004) to smoking (Corbett, Thompson, White, \& Taylor, 1991) to marriage (Doherty \& Anderson, 2004).

This increase in community interventions has occurred in part as recognition of the importance of targeting large numbers of people to effect broad social change. The increase also stems from a greater understanding that neighborhood and community attitudes have the ability to influence the attitudes and behaviors of individuals and families and thus communities are integral to the change process (Connell, Kubisch, Schorr, \& Weiss, 1995). More recently, community level interventions to combat social problems have become accepted modes for prevention and intervention (Wandersman \& Florin, 2003), and there is a growing belief in the importance of citizen participation and community empowerment over top-down social engineering (Beresford \& Croft, 1993; Peterson \& Lupton, 1996).

Communities are integral to the health and well being of families and family professionals can have an important role in working with families in their community. This article introduces family professionals to a democratic citizen model of community organizing for mobilizing and partnering with families, applying it here to the overscheduling of children and the consequent decline of family time. This article highlights an alternative approach to professional community engagement, that of the citizen professional who works alongside members of the community to initiate and develop interventions for community change. We 
believe this approach will be useful to a broad range of family professionals who are interested in partnering with families to affect broader community and social change. We begin with an overview and discussion of the growing body of research around the issue of family time. We then describe the difference between our citizen model and program models of engaging families, give two examples of family time community initiatives, describe next steps for evaluating this community organizing model, and offer implications for family professionals.

\section{Research on Family Time and Children’s Schedules}

Community projects benefit from good data to back up personal experiences and community-wide perceptions. It has been our experience that when citizens hear that there is empirical data that validates their concerns, they are more highly motivated to engage the issue publicly. In the case of the overscheduling of children, research began to accumulate around the year 2000. The most important study is Sandra Hofferth's (2001) analysis of two waves of the Panel Study of Income Dynamics, which assessed different national probability samples of American families with children ages 3-12 in 1981 and 1997, using time dairies completed by parents. Hofferth found that children became far busier during the last two decades of the twentieth century, and that families spent less time together. Specifically, she reported the following changes in children’s time: free time declined by 12 hours per week; playtime decreased by three hours per week; unstructured outdoor activities fell by 50 percent; study time increased by almost 50 percent; family mealtime declined by one hour per week; household conversations dropped by 100 percent, with the average American family spending no time per week when talking was the primary activity for the whole family; structured sports time doubled to over five hours per week; and passive, spectator leisure (mostly watching others play) increased five-fold to three hours per week. 
These findings are supported by Robert Putnam’s (2000) analysis of annual data conducted for the DDB Needham Life Style Surveys, which has polled a representative sample of married couple households on a yearly basis since 1977. Putnam reported a decline of 33\% from 1977-1999 of respondents who say, “our whole family usually eats dinner together.” The drop was from $50 \%$ of families to $34 \%$ of families. Interestingly, Putnam also reports that, although TV watching has increased in American homes, watching TV as a family declined by nearly $25 \%$ during this period. He also reports a $28 \%$ decrease in the number of families taking vacations each year.

Although little research is available about whether these changes in children's and families' time have negative outcomes, evidence is accumulating on the positive role of family meals for children and the negative impact of having few family meals. Hofferth (2001) found that time spent eating meals at home was the strongest predictor of children's academic achievement and psychological adjustment. The Council of Economic Advisers to the President (2000), in an analysis of data from the national Adolescent Health Survey, found that having five or more dinners per week with a parent was a strong predictor of a wide range of adolescent strengths. Gillman et al. (2000) found that children who ate more family dinners at home had better quality diets on a variety of nutritional indices, and Ackard and Neumark-Sztainer (2001) found that family meal time while growing up is associated with fewer symptoms of eating disorders among college age women.

One question about these studies on family meals is whether frequency of family meals is a cause or effect of family cohesion; perhaps meals are just a stand in for cohesion, which might be the true predictor of children's well being. Eisenberg, Olson, Neumark-Sztainer, Story, \& Bearinger, (2004) examined this question in a large sample of school age children in Minnesota. 
They found the same broad correlates of children's well being associated with frequency of family meals, and then statistically controlled for a measure of family connectedness. The relationship between family meals and children's outcomes remained strong. All of these studies controlled for income, family structure, and social class factors. In sum, research evidence suggests that current levels of children's schedules and the decline in family time, especially mealtime, may have important implications for children and families.

These changes in family time and children's activities have increasingly led to time intensive, hyper-competitive activities, less unstructured play time for children and less family time including family meals (Doherty \& Carlson, 2002; Rosenfeld \& Wise, 2000). Recent polling data (Center for the New American Dream, 2003; Anderssen \& McIlroy, 2004) has shown that parents (especially middle class parents) have become increasingly aware and concerned about these trends, yet feel powerless in their ability to make changes and stem the tide. A Search Institute poll found that $41 \%$ of parents said that their "child being overscheduled in so many activities” made parenting difficult (Roehlkepartain, Scales, Roehlkepartain, Gallo, \& Rude, 2002, p. 9). This ranked with financial concerns as the third most problematic issue that made parenting difficult, just behind “job demands” and “conflicts or rivalries among children” (Roehlkepartain et al., p. 9). In the next section we will describe how a program model aimed at individual families would approach the issue of overscheduled children, and then we present a citizen model that engages parents in tackling the problem at the community level.

Approaches to Intervention with Individuals and Families

\section{Traditional Program Approach}

The goal of program approaches is to provide support and education to individual families or small groups of families in order to increase their well being (Fitzpatrick, Sanders \& 
Worthen, 2004; Thomas \& Arcus, 1992). Most often family professionals take primary responsibility for defining the problem and developing the curriculum or intervention (Dumka, Roosa, Michaels \& Suh, 1995; Hughes, 1994; Goody \& Kozoll, 1995). A program targeting the problem of overscheduled children might begin with a family professional noticing that parents in a community are becoming increasingly stressed over the time crunch related to children’s schedules. After reviewing the professional literature, the family professional might seek information from parents in the community about this phenomenon, eliciting personal stories to better understand the problem. The family professional might begin to speak about this issue in public presentations such as PTA meetings, community education programs, and professional meetings. These initial presentations might be followed by the development of workshops or classes at local agencies, civic organizations, schools and faith communities. Such presentations are often grounded in theory and research and are packaged in a way to educate, inspire, and offer assistance to individual families. The program usually has a fixed beginning and end, based on the professional's availability and sense of how much time parents will commit. Success typically is defined by the number of families that participate, parent evaluations, and perhaps the incorporation of the new program into existing services provided by the supporting or sponsoring organization. More elaborate evaluation may then ensue, using more formal research tools if funding is available (Dumka et al., 1995; Goody \& Kozoll, 1995; Tolan \& McKay, 1996).

This familiar model of intervention and education continues to be a valid approach to working with families today. In fact, we started our work in the area of family time in much the same way-gathering stories, learning about the phenomenon, and speaking about the issue to parenting groups and civic organizations. But, program approaches to intervention are primarily 
educational in nature, target individual families, and do not provide the tools to engage families as change agents in their communities. We believe this approach is limited when the goal is broader community and cultural change that affects large numbers of families (Wandersman \& Florin, 2003). In the next section we describe a citizen model of community organizing and intervention that emphasizes democratic partnership between professionals and families to tackle important issues at the community level. Table 1 provides a comparison of the program and citizen models.

Table 1

Program Approach vs. Citizen Approach

Dimension of Practice PROGRAM CITIZEN

$\underline{\text { Scope of Practice }}$

What is the scope

Individual families

Communities of families of practice?

\section{$\underline{\text { Process Leadership }}$}

What is the family's role?

Who leads the process?

We defines the problems?

Who develops the intervention or curriculum?

Location \& Duration
Learner/client $\quad$ Co-creator, producer

$\begin{array}{ll}\begin{array}{l}\text { Professional, though } \\ \text { often collaboratively }\end{array} & \begin{array}{l}\text { May begin with } \\ \text { collaborative } \\ \text { professional leadership, } \\ \text { but becomes family-led }\end{array}\end{array}$

Professional, after Communities of families assessing needs; or are the main definers, individual family with professional input requesting help

Professional Jointly generated from the outset 


$\begin{array}{lll}\begin{array}{l}\text { Where does the } \\ \text { work occur? }\end{array} & \begin{array}{l}\text { Professionally- } \\ \text { determined site }\end{array} & \begin{array}{l}\text { Jointly-determined sites } \\ \text { and locations }\end{array} \\ \begin{array}{lll}\text { What is the time } \\ \text { frame for the work? }\end{array} & \begin{array}{l}\text { Tightly bounded } \\ \text { appointments. }\end{array} & \begin{array}{l}\text { Jointly decided meeting } \\ \text { times, duration of }\end{array} \\ & \begin{array}{l}\text { Duration determined } \\ \text { by professional }\end{array} & \begin{array}{l}\text { initiatives often open- } \\ \text { ended }\end{array}\end{array}$

\section{$\underline{\text { Orienting Ideal }}$}

What is the orienting ideal?

$$
\begin{array}{ll}
\begin{array}{l}
\text { Educating or taking } \\
\text { good care of families }
\end{array} & \begin{array}{l}
\text { Creative partnership to } \\
\text { activate families as } \\
\text { builders of their world }
\end{array}
\end{array}
$$

Note. Adapted from Doherty \& Carroll (2002).

\section{The Families and Democracy Model}

The Families and Democracy Model offers a framework for working with families as active citizens in communities. It uses community organizing strategies rather than program strategies and operates under the assumption that strengthening families must be done mostly by families themselves, working democratically in local communities. Thus, in this approach, citizens are active producers of change in their communities and are involved at every step of the initiation and development of community intervention, with family professionals serving as catalytic leaders and citizen professionals who work alongside citizen families.

The Families and Democracy Model, developed by Bill Doherty, evolved out of a series of conversations with Harry Boyte and Nancy Kari at the Center for Democracy and Citizenship at the University of Minnesota (Boyte \& Kari, 1996; Doherty \& Carroll, 2002). In their “public work model," public work is defined as “sustained, visible, serious effort by a diverse mix of ordinary people that creates things of lasting civic or public significance” (Boyte, 2002, p. 1). The Public Work Model is rooted in American pragmatism and is a practice-oriented approach to community engagement. It conceptualizes human beings as producers and co-creators of the 
world and stresses the importance of "public" life and democratic, relational power. In this way of thinking, institutions and communities can be transformed by the actions of ordinary individuals coming together as citizens through a democratic process (Boyte, 2004; Boyte, Kari, Lewis, Skelton, \& O’Donoghue, 2000).

The Families and Democracy Model provides a set of principles and strategies whereby family professionals partner with communities of families to work toward democratic community action (See Appendix A). In this model, family professionals and citizens come together to tackle problems of mutual interest where every person brings a different kind of expertise and therefore everyone has both something to learn and something to contribute. Families do not just add their individual wisdom to professional knowledge; rather the process is a blending of professional knowledge and the wisdom of communities of families that results in families serving as co-creators and producers of community change (Doherty \& Beaton, 2000; Doherty \& Carroll, 2002).

The model sets forth both grounding principles and a process for action. Community initiatives engage citizens at every stage of the process, from defining problems and solutions to mobilizing community resources for action. Therefore the specific kind of action a community of families will take is not predetermined. For example, it would not be consistent with this model for a professional to propose an established intervention program at the beginning of a project. But a citizen group might decide to create a program or to adopt a program as one of its activities. The model provides the principles to guide the process of developing action initiatives and the strategies to carry out those initiatives to ensure that the action taken is community owned and community initiated. 
In addition to these process issues, a key distinction between a citizen model such as the Families and Democracy Model and other approaches is in the level of intervention. Professionals partner with communities of families in order to bring about change at both an individual family level and the community level. Community here is defined broadly, where there "is a sense of affiliation that sets some boundaries and clarifies who is in and out of the community system, along with a sense of common concern about an issue or challenge” (Doherty \& Carroll, 2002, p. 585). Thus, a community can include any number of groups such as schools or school districts, local service agencies, neighborhoods or neighborhood associations, religious congregations, medical clinics, or any number of "groups with common interests.”

What also makes these partnerships distinct is the sense of a larger purpose and the public nature of the work. Local problems are tackled pragmatically through a democratic process with an eye toward transformation of the community and the larger culture. For example, in family time initiatives, the goal is not just to help individual families retrieve a balance in their family life but to create intentional communities that value, encourage, and honor family time. Part of the public nature of this work is generating public visibility on the issue and the initiative through an intentional media strategy and through visible community events. This serves to bring the issue into the community's collective awareness as well as to recruit new leaders as citizen partners into the initiative. Citizen models often begin with professionals leading the initial stages of an initiative, with the goal of developing citizen leaders for the next phases of the initiative. Professionals serve as resources whose knowledge and expertise is “on tap,” not “on top.”

Since 1999, we have used this model of community organizing and mobilization in ten communities working on diverse issues (Doherty \& Carroll, in press). The work is not just about 
intervening with families in communities, but also about a vision of professional practice as a form of democratic citizen work. The next section will outline two community initiatives that focused on the issue of overscheduled children where the authors played active roles as speakers at public events and facilitators of the process. Our roles were more central at the outset and more supportive of parent leaders in the later stages. We describe the process of community mobilization in some detail in order to demonstrate how this approach differs from program approaches.

\section{Family Time Community Initiatives}

The process for developing family time initiatives is outlined in Appendix B. Like the principles and strategies of the Families and Democracy Model, the process for developing family time initiatives was developed by Doherty and is based on the Public Work Model's approach to community engagement (Boyte \& Kari, 1996; Boyte, 2004). We have found that it takes a project about one year of incubation and planning before action initiatives can be publicly launched. This results in one of the constant tensions of this work, balancing the desire to take immediate action with the desire to allow, at times, for the slow and messy process of democratic community engagement. We believe that a deliberate, intentional development and planning period is vital when trying to tackle large, entrenched cultural problems through a process that requires consensus and deep reflection. And yet, sometimes the initiatives can get bogged down in the process of consensus and reflection when there is no timetable for action. In an attempt to bridge this tension, newer projects have been conceptualized as two-year campaigns that allow for deep reflection and provide a definable timetable for action.

The one-year incubation period includes forming an initial group to plan a public meeting in the community. As a result of this public meeting, a citizen planning group is created that 
names the project; creates a mission and begins to articulate the reasons and public purposes for the project; conducts stakeholder interviews throughout the community; develops a wide range of potential action initiatives that are consistent with the Families and Democracy Model; and finally, chooses several specific action initiatives to launch at a second public event. This second public event, or launch event, begins the second year of the two-year campaign. It is at this public launch of the action initiatives that additional citizens join the project and develop action groups to begin the task of putting the action initiatives on the ground. What follows are two examples of family time initiatives where citizen parents and citizen professionals joined together to change the culture of their communities around the issue of family time.

\section{Putting Family First}

We became involved in community action around the issue of overscheduled kids and underconnected families almost by accident. In April 1998, Doherty was invited to give a keynote talk to a large conference for parents in Wayzata, Minnesota on the topic of family time and family rituals. In his talk, Doherty raised up the problem of the loss of family time to outside activities for children, and the importance of taking back family life from overscheduled family hyperactivity and the consumer culture of childhood. Parents responded enthusiastically to the message, but seemed at a loss about how to turn back the tide of over-busyness. Several school and community officials reflected in private that their organizations unintentionally contribute to this problem by offering more and more activities for children and youth, without alerting parents to the inevitable toll on family time that these activities take.

Later in 1998, Doherty was invited to return the next spring to give a similar talk as part of a lecture series on parenting. He declined, saying that he only gives the same talk once in a community, but that if Wayzata wanted to organize to take action on the problem, he would 
return to help with that process. In subsequent discussions with Barbara Z. Carlson, the local leader who made the invitation, Doherty suggested an approach to civic engagement based on the Public Work model (Boyte \& Kari, 1996).

In April 1999, Doherty gave a talk and facilitated a town meeting for which Barbara Carlson and her colleagues had extensively advertised and recruited parents and community leaders to attend. About 300 parents attended the talk, and afterwards about 85 people went to a smaller room for the town meeting. Consensus emerged that the problem of declining family time was a community problem, not just an individual family problem. At the end of the town meeting, parents and community leaders signed up for a visioning and planning group to provide leadership for a grass roots movement to make family life a higher priority in their community. Putting Family First was the name given to this community initiative. This was the launching of the first community project in the country on the problem of overscheduled kids and underconnected families.

Over the next year the leadership group set about developing a mission, a desired future, and a vision of what the community could be if both individual families and community institutions put family first. The leadership group took the important step of conducting stakeholder interviews throughout the community in order to understand how members of the community saw the problem, what resources or solutions they had for tackling the problem, and whether or not they would be interested in joining future initiatives. In this model it is vital to continue to identify and develop new leaders. New leadership infuses the initiative with energy and ideas, which helps to prevent burnout and ensures that the community initiative continues. We have also found that bringing in new citizens to learn the model and then to lead helps to reduce rigidity and entitlement that can sometimes seep into the system when individuals begin 
to see the work as "their own” rather than the work of a community of citizens that are mutually engaged.

In the spring of 2000 the public launch event was held. Community action initiatives were presented and attendees were invited to participate in putting the new initiatives on the ground, with the previous leadership team splitting up and serving as leaders to the new initiatives. There were several initiatives that developed from this process: a Putting Family First Seal of Approval, which would be given to organizations and businesses whose policies and practices support balancing outside activities with family time; a Consumer Guide which provided parents with a detailed analysis of the time and financial demands of local children's activities such as sports and music programs which helped parents to make informed choices about what to enroll their children in; a faith community partnership; an on-line internet discussion group for parents; a book titled Putting Family First: Successful Strategies for Reclaiming Family Life in a Hurry-Up World; and a focused approach to generating intense media attention around the subject of family time and about the initiative both locally and nationally. The Putting Family First initiative now functions independently of professional involvement, having incorporated itself as a non-profit. A leading current initiative is creating community buy-in for a Family Night during which all community activities are cancelled so that families can be together as families. The power of this kind of project, started first in Ridgewood, New Jersey, lies not in a once per year family night but in the agreement of all community stakeholder groups — including sports, faith communities, and arts groups — to recognize the importance of family time by canceling their activities on the same night. Time IN For Family 
Two family time initiatives began in the summer of 2003, one in Eden Prairie, Minnesota (Family Time First) and one in Southwest Minneapolis (Time IN For Family). The two initiatives are currently in similar stages of action and they followed the same process in their development, therefore only one will be described here. Time IN For Family is a community initiative in Southwest Minneapolis with a mission of changing the culture of overscheduled and underconnected families by breaking down barriers to putting family time first. Like Putting Family First, Time IN For Family began with a community talk by Doherty that served as an initial community conversation about whether the community felt families were overscheduled and whether they were interested in taking collective action.

The initiative is now in the second year of a two-year campaign but it was this initial community talk and town meeting that set the stage for community action. That event, along with local media coverage of the event, created the initial buzz and raised the community's collective awareness about the issue. In addition to print media, the local public television station taped both the talk and town meeting, which was shown several times over the ensuing months. The citizens at this initial event determined that this was an issue their community was facing and that a community effort was needed to deal with the problem. After the town meeting about two-dozen citizens came forward to join the planning group that would direct the initiative in the community over the next year and a half. This group met monthly over the next nine months to create a name for the initiative, articulate a mission, examine the issue in their own lives, in the community and in the culture, generate preliminary action ideas, and conduct stakeholder interviews. There are three criteria for choosing action initiatives when using the Families and Democracy Model. The action ideas must be consistent with the model, individuals in the planning group must be enthusiastic and energized about the action idea, and there must be 
individuals within the planning group that are willing and able to lead the initiative. We have also learned that it is important for Families and Democracy Projects to choose a minimum of two action initiatives. This helps to ensure that the project is not defined by a single initiative and so the fate of the project does not rest on the outcome of one action idea.

Time IN For Family chose two action initiatives from the list of preliminary ideas to launch in the community. The first is an attempt to reclaim the family dinner hour and encourage families to carve out and protect this time for connection and sharing. The second initiative addresses the overscheduled and highly structured lives of children by working to create alternatives within the community that allow for a balance between family time and youth sports participation. These initiatives were presented to the community during a community launch event and additional citizens were recruited to begin the process of implementing the initiatives in the community. The launch event was cosponsored by the local PTA/PTO organizations and media coverage leading up to the event included brief reporting of the event in the major local newspaper and in one national newspaper (Wall Street Journal). The mayor of Minneapolis attended the event with his wife and they both spoke in support of the initiative. (The mayor described how he has arranged his City Hall staff schedule so that he and his staff can be home between 6-7 p.m. for dinner, even if they have evening meetings later. He noted that it is easier to manage his mayor's schedule than his kids’ sports schedules.) They were the first family to sign the "pledge" to commit to sharing four or more dinners a week together as a family over the next six months. A key component of the family dinner initiative will be a community event to gather family stories about the effect taking the public pledge had on participating families as well as obtaining family stories about family rituals that enhanced the family dinner experience. 
This community wisdom and experience will be fed back to the community through newsletters, web postings and possibly the development of a handbook of community "best practices."

These two action initiatives are seen as the initial steps toward accomplishing the mission of changing the culture within Southwest Minneapolis around the issue of family time. Although the citizens currently engaged in the initiative recognize that these two action steps alone will not reorient the community overnight, they understand that what they are doing influences the larger cultural conversation and begins to offer an alternative message to the current mantra that more is better. As the community begins to take measurable steps to reclaim and elevate the importance of family time and community connection additional action initiatives will be possible as the number of citizens engaged in the process swells and as the issue begins to seep into other aspects of public life.

Implications for Future Research and Evaluation

\section{Evaluative Readiness}

The Families and Democracy Model has been used to organize over ten communities around a variety of issues over the past five years. Through these experiences, the process and activities for implementing the principles and strategies outlined in the model have been revised and honed (see Appendix A). We believe the Families and Democracy Model meets the criteria for what Campbell (1984) called a "proud program” or for our purposes, a "proud community organizing strategy.” That is, the program or strategy has had time to mature and has undergone a process of revision and refinement based on its application in a variety of contexts and settings and is considered to be worthy of use by others. Given this stage of development and the clear specification of the community organizing activities, purposes, and intended results we believe 
the model is "evaluable” or ready to be evaluated (Mancini, Marek, Byrne, \& Huebner, 2004; Rossi, Lipsey, \& Freeman, 2004).

Evaluative Strategies

We see two main avenues of future investigation. The first is to determine the extent to which the process of community organizing outlined by the model occurs in actual practice and how effective the process is in organizing and engaging the community around the issue of family time. If it is determined that the model is being implemented as theorized and is found to be effective in mobilizing communities of families, then the second step would be to determine the level of effectiveness of the community initiative on the community's attitudes, behaviors, and actions around the issue of family time. The first step is often referred to in the literature as a process evaluation, while the second step is commonly known as an outcome evaluation (Rossi et al., 2004). The sequencing of these investigations is important, in that it is prudent to first determine whether or not the community can actually be engaged as theorized before an attempt is made to determine what kind of difference or impact the initiative had on the community (Israel et al., 1995). Given the development of the model, we will limit our discussion to process evaluation strategies that we feel are consistent with the democratic approach of community organizing. Action research and participatory evaluation approaches are two methods that could be useful in understanding the effectiveness of engaging communities using the Families and Democracy Model.

Action research. Also known as participatory action research, action research is a mode of inquiry rather than an evaluation approach that is particularly suited for studying democratic community initiatives (Greenwood \& Levin, 1998; Reason \& Bradbury, 2001). In this approach, the development and evaluation of programs and initiatives occur simultaneously as researchers 
and program participants collaborate to evaluate the process and outcome of an initiative in order to create knowledge and effect change. The approach is participatory and democratic in that all individuals are involved in the creation, implementation, and evaluation of the project at each stage of the process and each person is seen as an equal contributor, thus flattening the typical researcher/participant hierarchy (Greenwood \& Levin). The process is cyclical in that (a) a specific problem is defined that is important to all participants and information is gathered to understand the nature of the problem in context; (b) solutions to address the problem(s) are developed and refined; (c) interventions are implemented; and (d) outcomes that are meaningful and specific to the needs of the community are evaluated and the intervention is modified (if indicated) as a result of the information obtained in the first three steps (Mendenhall \& Doherty, in press). In action research, it is a given that "not everything is known” when the project begins. This requires an iterative process where participants constantly reflect on the process, remain open to new ideas and maintain flexibility as the group proceeds through a course of action that often seems slow and messy. Action research provides important information about the development and implementation of community initiatives and therefore is a good approach for conducting process evaluations in democratic community initiatives. Without an understanding of how the program/initiative was implemented, it is difficult to interpret outcome data (Israel et al., 1995). Mendenhall and Doherty (2003) studied one Families and Democracy project, Partners in Diabetes, with action research methods, and found that the project was implemented in accord with the model, including achieving a flattened hierarchy and activating lay leaders.

Participatory evaluation approaches. Another promising mode of inquiry for the evaluation of democratic community initiatives is participatory evaluation approaches. Like action research, the many approaches to participatory evaluation share in common the 
importance of involving members of the community as partners and co-creators of the evaluation process. They include involving stakeholders representing diverse aspects of the community in the development of the evaluation process and the interpretation of the evaluation data (Bryk, 1983; Mark \& Shotland, 1985); a focus on subsuming power imbalances and ensuring that all relevant interests are represented in the evaluation so that decisions are made and conclusions are drawn through an open, careful, deliberative democratic process (House \& Howe, 1999); and finally, transforming the evaluation process from a partnership between evaluators and community members to empowering individuals in the community through a process of mentoring to conduct evaluations themselves (Fetterman, 1994). These three approaches, stakeholder-based evaluation, deliberative democratic evaluation, and empowerment evaluation and the principles that inform them have the potential to guide the development of an investigation into the effectiveness of the community organizing strategy known as the Families and Democracy Model.

\section{Implications for Family Professionals}

The growing body of research documenting a decline in family time, coupled with parents’ increasing concerns about children’s schedules, provides a rich opportunity for joint citizen action through a parent/professional partnership. In addition to the three communities we have worked with, other communities have either begun initiatives (Ridgewood, NJ and Sidney, NY) or are contemplating initiatives (a suburban Minneapolis community). The citizen model of democratic partnership described in this paper offers a template for family professionals who are interested in engaging their communities around the issue of family time and we believe that family professionals are well positioned for this work. Family professionals, as trusted experts on issues related to family life, can bring research to bear and provide the rationale and motivation 
for community action and engagement. If the family professional also has the process skills for community organizing, he or she can act as a catalyst to jump-start the citizen movement and serve "alongside” as a fellow citizen as the initiative develops. This approach gives family professionals another tool in their work with families and communities.

The growth of community initiatives and community engaged projects is in part the result of professional recognition that programs and interventions need to be imbedded in the values and culture of the community that the programs intend to serve. In addition, citizen involvement and co-creation of initiatives helps to ensure that the targeted social issues are important to the community and that the interventions are relevant (Wandersman \& Florin, 2000). Citizen involvement may also increase the likelihood that the project and the interventions that emerge will continue after funding runs out or professionals have moved on to other projects or activities. Therefore, it is important for family professionals to work alongside (and not above) citizens in communities to envision, develop, and maintain initiatives that promote positive community change.

Though the focus of this paper has been on our work with the overscheduling of children, this model of community organizing has been used in a variety of communities focusing on diverse issues. Since 1999, pilot Families and Democracy initiatives have been developed in medical settings, faith communities, and public and private agencies. Communities have organized around diabetes care, strengthening marriage, the faith development of children, and the development of community engaged parent education. Although until recently the projects have worked mainly with White, middle class families, two new Families and Democracy projects, started in the fall of 2004, focus on depression in the Hmong community (Doherty, 
2004) and unmarried new parents in urban communities. Experience suggests that the model can be used in a variety of settings for a number of potential community problems or issues.

Next steps in the development of the model include learning how to mentor greater numbers of family professionals in the skills of community engagement and in testing the effectiveness of the community organizing strategies. A mentorship model is used in the training of interested and activated family professionals to develop the skills and learn the process of democratic community engagement. One current Families and Democracy Project, Community Engaged Parent Education, currently has funding to train about 40 parent educators over a twoyear period in facilitating citizen dialogue and public action as part of regular parent education. What is learned from this project will greatly assist us in developing and disseminating a model for mentoring family professionals in the Families and Democracy Model. As outlined in the section on evaluation, important next steps in testing this model are in determining the extent to which the strategies used by the model are effective in mobilizing the community to promote change.

In closing, our experience is that this is energizing and enjoyable work for the family professional. It provides professionals with the opportunity to become more fully engaged in their local communities and expands their sense of professional contribution. It provides new ways of tackling problems and infuses the intervention process with creative solutions when citizens (both lay and professional) offer their wisdom, experience, and energy to the process. 


\section{References}

Ackard, D. M., \& Neumark-Sztainer, D. (2001). Family mealtime while growing up: Associations with symptoms of bulimia nervosa. Eating Disorders, 9, 239-249.

Alinsky, S. D. (1969). Reveille for radicals. New York: Vintage Books.

Anderssen, E., \& McIlroy, A. (2004, April 10). Quebec distinct in nursery too, poll finds. The Globe and Mail, Online Edition. Retrieved April 11, 2004 from www.theglobeand mail.com

Beresford, P., \& Croft, S. (1993). Citizen involvement: A practical guide for change. Basingstoke, England: Macmillan.

Boyte, H. C. (2004). Everyday politics: Reconnecting citizens and public life. Philadelphia, PA: University of Pennsylvania Press.

Boyte, H. C. (2002). What is public work? Monograph available from the Center for Democracy and Citizenship at the University of Minnesota: www.publicwork.org

Boyte, H. C., \& Kari, N. N. (1996). Building America: The democratic promise of public work. Philadelphia: Temple University Press.

Boyte, H. C., Kari, N. N., Lewis, J., Skelton, N., \& O’Donoghue, J. (2000). Creating the commonwealth: Public politics and the philosophy of public work. Dayton, $\mathrm{OH}$ : Kettering.

Bryk, A. S. (Ed.). (1983). Stakeholder-based evaluation [Special Issue]. New directions for program evaluation, 1983(17).

Campbell, D. T. (1984). Can we be scientific in applied social science? In R. F. Conner, D. G. Altman, \& C. Jackson (Eds.), Evaluation studies: Review annual (Vol. 9, pp. 3537). Beverly Hills, CA: Sage. 
Center for the New American Dream. (2003, February). What do kids really want that money can't buy? Retrieved October 2, 2004 from http://www.newdream.org/ publications/bookrelease.php

Connell, J. P., Kubisch, A. C., Schorr, L. B., \& Weiss, C. H. (Eds.). (1995). New approaches to evaluating community initiatives: Concepts, methods, and contexts. Washington, DC: Aspen Institute.

Corbett, K., Thompson, B., White, N., \& Taylor, M. (1991). Process evaluation in the community intervention trial for smoking cessation (COMMIT). International Quarterly of Community Health Education, 11, 291-309.

Council of Economic Advisers to the President. (2000). Teens and their parents in the $21^{\text {st }}$ century: An examination of trends in teen behavior and the role of parental involvement. Retrieved August 4, 2005 from http://clinton3.nara.gov/WH/EOP/CEA/ html/Teens_Paper_Final.pdf

Doherty, W. J. (2004). Finding the right lever: The citizen therapist making a difference in the larger world. The Psychotherapy Networker, November/December, 44-47, 50-51, 68.

Doherty, W. J., \& Anderson, J. R. (2004). Community marriage initiatives. Family Relations, 53, 425-432.

Doherty, W. J., \& Beaton, J. M. (2000). Family therapists, community, and civic renewal. Family Process, 39, 149-161.

Doherty, W. J., \& Carlson, B. Z. (2002). Putting family first: Successful strategies for reclaiming family life in a hurry-up world. New York: Henry Holt.

Doherty, W. J., \& Carroll, J. S. (in press). Families and therapists as citizens: The Families and Democracy Project. In E. Aldarondo (Ed.), Promoting social 
justice through mental health practice. Mahwah, NJ: Erlbaum.

Doherty, W. J., \& Carroll, J. S. (2002). The families and democracy project. Family Process, 41, 579-589.

Dumka, L. E., Roosa, M. W., Michaels, M. L., \& Suh, K. W. (1995). Using research and theory to develop prevention programs for high risk families. Family Relations, 44, 7886.

Eisenberg, M. E., Olson, R. E., Neumark-Sztainer, D., Story, M., \& Bearinger, L. J. (2004). Correlations between family meals and psychosocial well-being among adolescents. Archives of Pediatric and Adolescent Medicine, 158, 792-796.

Fetterman, D. M. (1994). Empowerment evaluation. Evaluation Practice, 15, 1-15.

Fitzpatrick, J. L., Sanders, J. R., \& Worthen, B. R. (2004). Program evaluation: Alternative approaches and practical guidelines. Boston, MA: Pearson.

Gillman, M. W., Rifas-Shiman, S. L., Frazier, A. L., Rockette, H. R. H., Camargo, C. A., Field, A. E., et al. (2000). Family dinners and diet quality among older children and adolescents. Archives of Family Medicine, 9, 235-240.

Goody, A. E., \& Kozoll, C. E. (1995). Program development in continuing education. Malabar, Fl: Krieger.

Greenwood, D. J., \& Levin, M. (1998). Introduction to action research. Newbury Park, CA: Sage.

Hofferth, S. L. (2001). How American children spend their time. Journal of Marriage and the Family, 63, 295-308.

House, E. R., \& Howe, K. R. (1999). Values in evaluation and social research. Thousand Oaks, CA: Sage. 
Hughes, R. (1994). A framework for developing family life education programs. Family Relations, 43, 74-80.

Israel, B. A., Cummings, K. M., Dignan, M. B., Heaney, C. A., Perales, D. P., SimonsMorton, B. G., et al. (1995). Evaluation of health education programs: Current assessment and future directions. Health Education Quarterly, 22, 364-389.

Knight Foundation. (2004). Community partners program. Retrieved January 31, 2005, from http://www.knightfdn.org/default.asp?story=cpp/index.asp

Mancini, J. A., Marek, L. I., Byrne, R. A. W., \& Huebner, A. J. (2004). Communitybased program research: Context, program readiness, and evaluation usefulness. Journal of Community Practice, 12(1/2) , 7-21.

Mark, M. M., \& Shotland, R. L. (1985). Stakeholder based evaluation and value judgments: The role of perceived power and legitimacy in the selection of stakeholder groups. Evaluation Review, 9, 605-626.

Mendenhall, T. J., \& Doherty, W. J. (2003). Partners in diabetes: A collaborative, democratic initiative in primary care. Families, Systems \& Health, 21, 329-335.

Mendenhall, T. J., \& Doherty, W. J. (2005). Action research methods in family therapy. In D. Sprenkle \& F. Piercy (Eds.), Research methods in family therapy (pp. 100-118). New York: Praeger.

Peterson, A., \& Lupton, D. (1996). The new public health: Health and self in the age of risk. London: Sage.

Putnam, R. (2000). Bowling alone: The collapse and revival of American community. New York: Simon and Schuster.

Reason, P., \& Bradbury, H. (Eds.). (2001). Handbook of action research: Participative 
inquiry and practice. London: Sage.

Roehlkepartain, E. C., Scales, P. C., Roehlkepartain, J. L., Gallo, C., \& Rude, S. P. (2002). Building strong families: Highlights from a preliminary survey from YMCA of the USA and Search Institute on what parents need to succeed. Retrieved from http://www.abundantassets.org/pdfs/BSF-Highlights.pdf on November 18, 2004.

Rosenfeld, A. \& Wise, N. (2000). The overscheduled child: Avoiding the hyper-parenting trap. New York: St. Martin’s Press.

Rossi, P. H., Lipsey, M. W., \& Freeman, H. E. (2004). Evaluation: A systemic approach $\left(7^{\text {th }}\right.$ ed.). Thousand Oaks, CA: Sage.

Thomas, J., \& Arcus, M. (1992). Family life education: An analysis of the concept. Family Relations, 41, 3-8.

Tolan, P. H., \& McKay, M. M. (1996). Preventing serious antisocial behavior in inner-city children: An empirically based family intervention program. Family Relations, 45, 148155.

Trolander, J. A. (1987). Professionalism and social change: From the settlement house movement to neighborhood centers, 1886 to the present. New York: Columbia University Press.

Wandersman, A., \& Florin, P. (2000). Citizen participation and community organization. In J. Rappaport \& E. Seidman (Eds.), Handbook of community psychology (pp. 247-272). New York: Kluwer/Plenum.

Wandersman, A., \& Florin, P. (2003). Community interventions and effective prevention. American Psychologist, 58, 441-448. 


\section{Appendix A}

The Families and Democracy Model: Principles and Strategies

\section{Core Principles}

1. Strengthening families in our time must be done mostly by families themselves, working democratically in local communities.

2. The greatest untapped resource for strengthening families is the knowledge, wisdom, and lived experience of families and their communities.

3. Families must be engaged as producers and contributors to their communities, and not just as clients or consumers of services.

4. Professionals can play an important role in family initiatives when they learn to partner with families in identifying challenges, mobilizing resources, generating plans, and carrying out public actions.

5. If you begin with an established program, you will not end up with an initiative that is "owned and operated" by citizens. But a citizen initiative might create or adopt a program as one of its activities.

6. A local community of families becomes energized when it retrieves its own historical, cultural, and religious traditions about family life--and brings these into the contemporary world of family life.

7. Family and Democracy initiatives should have a bold vision (a BHAG--a big, hairy, audacious goal) while working pragmatically on focused, specific goals.

\section{Strategies for Creating Action Initiatives}

1. Employ democratic planning and decision making at every step.

2. Emphasize mutual teaching and learning among families.

3. Create ways to fold new learnings back into the community.

4. Continually identify and develop new leaders.

5. Use professional expertise selectively--“on tap,” not “on top.”

6. Generate public visibility through media and community events.

7. Forge a sense of larger purpose beyond helping immediate participants. 
Appendix B

An Example of the Process for Developing the Family Time Initiatives

I. Groundwork Phase-Tasks (Summer, 2003)

Initial leadership group meets a number of times to envision the initiative, plan the launch event, and recruit parents and community leaders to attend the event and join the planning group.

II. Public Launch Event-Goals (October, 2003)

- To put the issue on the community's radar screen

- To tap the community's worries, knowledge, and energy for the issue

- To get community buy-in for starting an initiative

- To recruit a planning group to lead the initiative

III. Planning Phase-Tasks (Nov.-June, starting with retreat, then monthly meetings)

- Articulate a mission

- Develop a name for the initiative

- Examine the family time problem in our own lives, in the schools and community, and in the larger culture

- Generate preliminary action ideas, using the Families and Democracy model, which emphasizes grass roots organizing, parent leadership, family-to-family learning, cultural change, public visibility, and a sense of larger purpose

- Interview Stakeholders in the Community in order to:

- Bring others' perspectives and ideas back to the group

- Find allies

- Discover promising efforts already underway in the community

- Uncover obstacles and points of inertia

- Get feedback on preliminary action ideas

- Generate a buzz in the community

- Invite others to join the movement during action phase

IV. Decide on Action Projects-Tasks (during second retreat in June)

- Develop a leadership structure

- Plan to involve a wide range of community members and groups

- If more than one action project emerges, develop action groups led by members of the planning group to carry out the initiatives

V. Public Launching of the Action Initiatives (September, 2004)

VI. End Initiative with a Celebration (June, 2005)

Ideas for follow-up initiatives might have emerged by this time 